\title{
Occupational Safety Culture of Workers at Shop Floor in Medium Scale Iron and Steel Industries of Punjab State in India: Development of Safety Index
}

Satnam Singh* and Lakhwinder Pal Singh

Department of Industrial and Production Engineering, NIT, Jalandhar, Punjab, India

\begin{abstract}
Safety Index has been considered as an important quantitative method used to track safety changes, ranking a problem and also helps in facilitating the decision-making process. The main objective of this research was to develop a new safety index for the workers of medium scale manufacturing industries of Punjab using Delphi method with involvement of means and weights of the factors. To check the validity of the factors content validity index (CVI) was used, by taking expert opinion. The reliability of safety index was also examined by the analysis of data collected from 30 medium scale iron and steel manufacturing industries of Punjab, 10 workers were selected from each industry in order to fill the questionnaire. After calculating the results the standard value of safety index was found to be equal to 21.02 and the analysis of survey data suggested that all the 30 medium scale industries were below the standards of safety index. It means very less safety measures are maintained in the industries of Punjab and the working environment is found to be dangerous and unsafe for the workers of these industries. The main reason behind this scenario is the lack of knowledge among the workers and the greed of owners who don't want to spend money on maintaining the safety measures.
\end{abstract}

It is recommended to management of industries to improve or maintain their safety factors, so that the workers should feel safe and comfortable at the workplace.

Keywords: Delphi method; Medium scale industries; Safety index

\section{Introduction}

India is a developing country and industrial growth has added a lot to the development of Indian economy. Small and medium scale industries have played a vital role in development of India by enhancing the goods production rate and also by providing employment to the larger section of people. With increase in number of small and medium scale enterprises, number of operational injuries or casualties has also been increased.

According to the WHO, in each year 3.5 million deaths happen due to the accidents in the workplace. According to the ILO (International Labor Organization) in each year about 50 million job related injuries happen in the whole world. And in every 15 seconds, a worker dies due to the work-related accidents.

As per the data provided by DGFASLI in the year 2012, there are 1383 fatal injuries (causing death) and 28441 non-fatal injuries (not causing death) occur in India. According to ILO, in each year around 43,000 people die in India due to work related problems [1]. The increase in number of operational accidents can be attributed to carelessness or lack of knowledge (about safety parameters) among workers and owners of these industries. The direct or indirect losses due to work related mortality and morbidity of workers have made this problem a major issue of vital importance among these industries. There are many industrial accidents occurring in India. The Bhopal Gas Heartbreak (1984) was the whirling opinion in the antiquity of safety in India. The numbers of occupational accidents are increasing day by day [2-9]. In case of Punjab, if the numbers of factories are increasing then number of accidents is also increasing as presented in Figure 1.

The development of Safety index has always fascinated researchers of current era because of its ability to impart changes to the functioning and working environment of various sectors. Although, many researchers have tried to develop safety index for various areas for over many decades, but to the best of our knowledge, no such study has been undertaken for Punjab region. Different methods viz. (Delphi method, Logistic regression method, fuzzy logic method and statistical analysis method using SPSS) for development of safety index have been reported in literature. Our work emphasizes on the development of safety index for the medium scale industries of Punjab region

\section{ACCIDENTS AND FACTORIES IN PUNJAB 2005-2011}

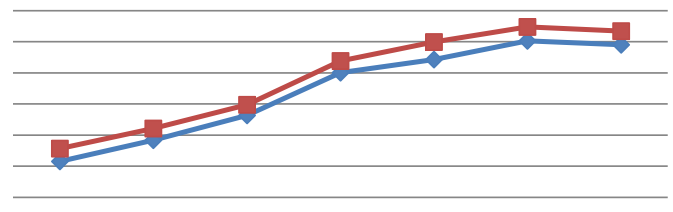

\begin{tabular}{|c|c|c|c|c|c|c|c|}
\cline { 2 - 8 } \multicolumn{1}{c|}{} & 2005 & 2006 & 2007 & 2008 & 2009 & 2010 & 2011 \\
\hline —-ACCIDENTS & 204 & 187 & 171 & 189 & 283 & 226 & 220 \\
\hline$\multimap$-FACTORIES & 15579 & 15919 & 16318 & 17004 & 17214 & 17513 & 17453 \\
\hline
\end{tabular}

Figure 1: Graphical representation of accidents as per number of factories in Punjab from year 2005 to 2011.

*Corresponding author: Satnam Singh, Research Scholar, Department of Industrial and Production Engineering, NIT, Jalandhar, Punjab, India, Tel: +910181-2690301; E-mail: satnam_pisces@yahoo.com

Received February 20, 2017; Accepted February 21, 2017; Published February 25, 2017

Citation: Singh S, Singh LP (2017) Occupational Safety Culture of Workers a Shop Floor in Medium Scale Iron and Steel Industries of Punjab State in India: Development of Safety Index. J Steel Struct Constr 3: 126. doi: 10.4172/24720437.1000126

Copyright: (c) 2017 Singh S, et al. This is an open-access article distributed under the terms of the Creative Commons Attribution License, which permits unrestricted use, distribution, and reproduction in any medium, provided the original author and source are credited. 
using Delphi method. The principal merit of Delphi method is that it depends upon the judgment of selected experts after series of intensive questionnaire (keeping current scenario in mind) and does not rely upon the previous data available [10-15].

Classification of different enterprises According to the Micro, Small and Medium Enterprises Development (MSMED) Act, 2006 for the manufacturing sector with respect to number of employees and investment has been represented in Table 1 [15-18].

\section{Methodology}

This study emphasized on the development of safety index for medium scale manufacturing industries. A total of 300 employees participated in this study who worked in 30 different manufacturing industries of Punjab, in order to collect required data for development of safety index.

Safety index is a measure of safety parameters followed by a particular manufacturing industry. Following are the general characteristics possessed by the safety index:

a) It should cover all the factors related to the occupational safety of workers.

b) It should provide precise and accurate information about the safety culture and its advances with respect to time.

c) It should provide platform or have scope of improvement in present scenario of occupational safety (Figure 2).

\section{Identification and validation of factors affecting occupational safety}

After following the above said methodology (step 1,2 and 3),

\begin{tabular}{|l|l|l|l|}
\hline S. no. & $\begin{array}{l}\text { Company } \\
\text { Category }\end{array}$ & $\begin{array}{l}\text { Number of } \\
\text { employees }\end{array}$ & $\begin{array}{l}\text { Investment in plant and } \\
\text { machinery }\end{array}$ \\
\hline $\mathbf{1}$ & Micro & $<10$ & $<25$ lakh rupees \\
\hline $\mathbf{2}$ & Small & $10-50$ & $>25$ lakh $<5$ crore rupees \\
\hline $\mathbf{3}$ & Medium & $51-250$ & $>5$ crore $<10$ crore rupees \\
\hline
\end{tabular}

Table 1: Category of the company according to the employees and investment.

\begin{tabular}{|c|c|}
\hline Step 1 & Literature review \\
\hline Step 2 & Identification of factors related to occupational safety \\
\hline Step 3 & Validation of factors by norms and expert's opinion \\
\hline Step 4 & Formation of questionnaire for data collection \\
\hline Step 5 & Expert's opinion on factors by Delphi method \\
\hline \multicolumn{2}{|c|}{$\downarrow$} \\
\hline Step 6 & \multicolumn{1}{|c|}{$\downarrow$} \\
\hline
\end{tabular}

Figure 2: Procedure followed for development of safety index.
9 major (Organizational Attributes, Occupational Safety Services/ documentation, Workplace Layout and Housekeeping, Equipment \& Hand Tools Safety and Machine Guarding, Fire Prevention, firefighting and electrical safety, Material Handling and Storage, Occupational Exposures, Personal Protective Equipment (PPE) and Hygiene Factors) and 42 minor factors were identified and validated using CVI (content validity index). Table 1 represents the identified factors.

\section{Content Validity Index (CVI)}

Content Validity Index (CVI) is a method used to validate the content, or in other words, used to check whether the factors coverall the disciplines for concerned area of interest. Six experts participated for content validation from medium scale manufacturing industry. Classification of CVI has been represented in Figure 2.

After the content validity, questionnaire has been developed for expert opinion to develop the safety index using Delphi method (Figure 3) [18-20].

\section{Determination of mean and weight for safety index using Delphi method}

Selected valid factors were used to take expert opinion on the developed questionnaire by Delphi survey method. The questionnaire was filled by 11 experts on the basis of 5-pointlikert scale i.e., ( $1=$ strongly disagree, $2=$ somewhat disagree, $3=$ neutral, $4=$ somewhat agree and $5=$ strongly agree).

$P i$ is the experts and $D j$ is the factors as $f i j$ where $i=1$ to 11 and $j=1$ to 16 . Where $i$ mean number of experts and $j$ means the number of factors.

The calculation method has been represented in Table 2 .

There are several steps while doing the Delphi Survey:

1. Select the relevant experts of the respective fields, who will fill out the survey anonymously.

2. The researcher has to conduct the survey.

3. The same experts are asked to fill out the questionnaire again by giving them the feedback that, how many of experts give the points to which of the indicators.

4. This procedure aims to assure that, the awareness of the expert view on the given questionnaire. These steps will be iteratively repeated as long as the experts do make changes on their judgments.

After this Delphi survey, we have to apply the below formula for the development of safety index [20-24].

$$
\mathrm{SI}=\sum_{i=1}^{n} w_{i} \sum_{j=1}^{m i} I_{i j}
$$

SI is the safety index, Iij is the value of each indicator within factors

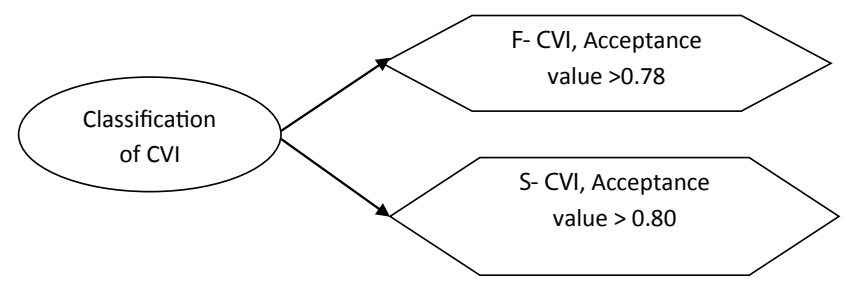

Figure 3: Schematic representation of CVI. 


\begin{tabular}{|c|c|c|c|c|c|c|c|c|c|}
\hline Factors & & & $D_{1}$ & $D_{2}$ & $\ldots$ & $D_{j}$ & $\ldots$ & $D_{n}$ & Description \\
\hline & & $P_{1}$ & $f_{11}$ & $f_{12}$ & $\ldots$ & $f_{i j}$ & $\ldots$ & $f_{1 n}$ & \\
\hline & & $\vdots$ & $\vdots$ & $\vdots$ & $\vdots$ & $\vdots$ & $\vdots$ & $\vdots$ & \\
\hline \multirow[t]{3}{*}{ Expert: } & & $P_{i}$ & $f_{i 1}$ & $f_{i 2}$ & $\ldots$ & $f_{i j}$ & $\ldots$ & $f_{1 n}$ & \\
\hline & & $\vdots$ & $\vdots$ & $\vdots$ & $\vdots$ & $\vdots$ & $\vdots$ & $\vdots$ & \\
\hline & & $P_{n}$ & $f_{n 1}$ & $f_{n 2}$ & $\ldots$ & $F_{n j}$ & $\ldots$ & $f_{n m}$ & $\ldots$ \\
\hline Mean: & $K_{j}=\sum_{i=1}^{n} f_{i j / n}$ & & $K_{1}$ & $K_{2}$ & $\ldots$ & $K_{j}$ & $\ldots$ & $K_{n}$ & \\
\hline Weight: & $W_{j}=\frac{K_{j}}{\sum^{n} K}$ & & $W_{1}$ & $W_{2}$ & $\cdots$ & $K_{j}$ & $\cdots$ & $W_{n}$ & $K_{j}=\sum_{j=1}^{n} W_{j}=1$ \\
\hline
\end{tabular}

Table 2: Delphi method to calculate the mean and weightage.

\begin{tabular}{|l|c|c|}
\hline & Calculation of Content Validity Index & Value \\
\hline Main Factors & 09 \\
\hline Total Sub Factor & 40 \\
\hline Factors Having F-CVI $>.078$ & 37 \\
\hline Mean F-CVI & 36.32 \\
\hline S-CVI & 0.98 \\
\hline
\end{tabular}

Table 3: F-CVI and S-CVI values for validation of factors.

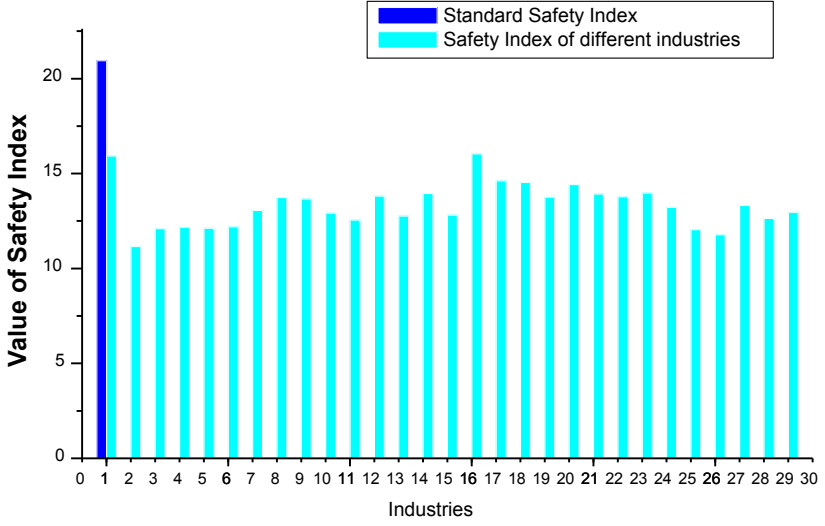

Figure 4: Level of Safety culture in different industries on the basis of standard safety index.

$i, w i$ is the weight of factors $i, n$ is the total number of index factors, $i$ identifies each factor, $j$ identifies each indicator within factor $i, m i$ is the number of indicator in each factor [24-28].

\section{Result and Discussion}

By conducting CVI, nine factors and thirty-seven sub factors that are necessary to be in the workplace for the safety of the worker were finalized on the basis of standard acceptance values of F-CVI and S-CVI i.e.,(F-CVI $>0.078$ and S-CVI $>0.98)$. Numerical values of F-CVI and S-CVI for validation of above said factors have been represented in Table 3.

The mean values of the score obtained for all the factors and sub factors related to occupational safety in medium scale manufacturing industries of Punjab has been represented in Table 4. As per expert opinion mean and weightage of all the factors were obtained and the data was utilized for the development of safety index. Mean and weight values of a particular factor represented its importance and contribution in operational safety culture. As per the data represented in Table 4, Personal Protective Equipment $\left(f_{8}\right)$ and hygiene factors $\left(f_{9}\right)$ were considered as most important factors (highest mean and weight values) of occupational safety. The calculated value of safety index using Delphi method was 21.02 (Table 3).

\section{Industrial implementation of safety index}

A questionnaire consisting of 37 questiones was designed to check the level of safety in 30 medium scale manufacturing industries of punjab. 10 workers per industry participated in the process of examining the reliability of safety index. The maximum value of sfatey index was found equal to 16.04 and the minimum value was 11.16. the average value of safety index in 30 different industries was 13.29 and the value was quite less as compare to stanard safety index (21.02) (Figure 4).

So the occupational safety culture among the medium scale manufacturing industries of punjab is very poor and it has been observed that it lacks in following safety factors:

- $\quad$ Personal Protective Equipment (PPE)

- Occupational Safety Services

- Organizational Attributes

The above said factors should be taken care of and consistancy in the remaining factors is required in order to provide safe and healthy working environment among the workers.

\section{Conclusion and Future Scope}

\section{Conclusion}

Saftey index is developed for the medium scale industries of punjab using Delphi method, and the value of stanard SI was found to be 21.02. On analysing the relaibilty of SI among the MSMI of Punjab, it was observed that safety culure was very poor and the operational safety of workers lacks primarily in four major and nine sub-factors. Operational safety of workers should be considered as a major concern and the improvement in safety factors is recommended for the better safety culture in the medium scale manufacturing industries of punjab. 
Citation: Singh S, Singh LP (2017) Occupational Safety Culture of Workers at Shop Floor in Medium Scale Iron and Steel Industries of Punjab State in India: Development of Safety Index. J Steel Struct Constr 3: 126. doi: 10.4172/2472-0437.1000126

Page 4 of 5

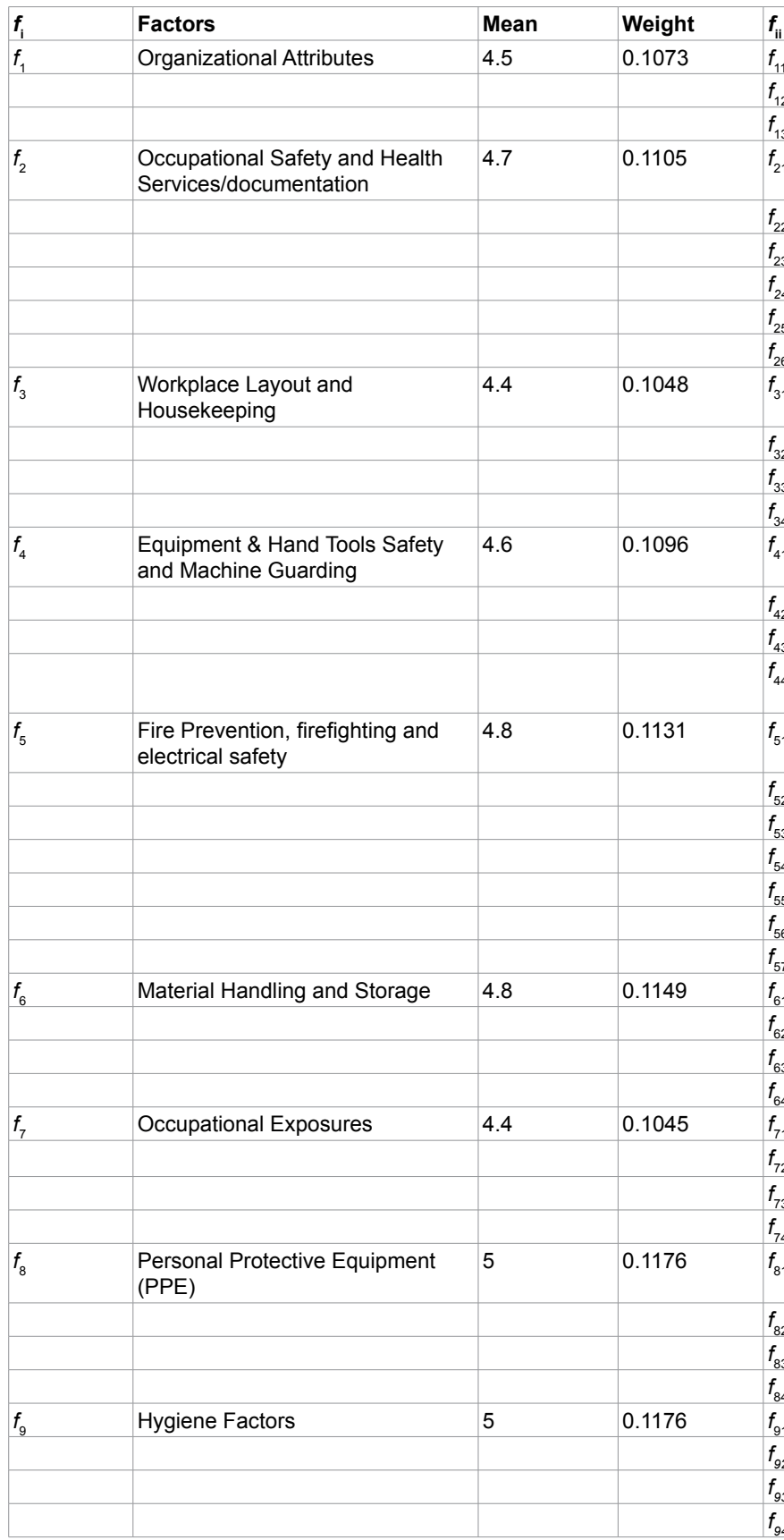

\begin{tabular}{|c|c|c|}
\hline Sub-Factors & Mean & Weight \\
\hline Requirement of Safety and health policy & 4.7 & 0.344 \\
\hline Requirement of safety department & 4.5 & 0.325 \\
\hline Qualified safety specialists/officers/engineer & 4.5 & 0.331 \\
\hline Facility for periodical medical examination & 5 & 0.178 \\
\hline Provision of Health/medical insurance & 5 & 0.178 \\
\hline Provision of first aid services & 5 & 0.178 \\
\hline Documentation of safety program & 4.9 & 0.175 \\
\hline Records of accident and injury & 3.3 & 0.117 \\
\hline Need of absenteeism records & 4.9 & 0.175 \\
\hline Adequate and smooth material flow & 4.6 & 0.262 \\
\hline Safe and smooth production line layout & 4.3 & 0.241 \\
\hline Neat and clean floors, walls and ceilings & 4.5 & 0.251 \\
\hline Provision of proper disposal of waste & 4.4 & 0.246 \\
\hline Need of periodic inspection & 4.5 & 0.246 \\
\hline Availability of proper machine guards & 4.6 & 0.251 \\
\hline Proper space for hand tools storage & 4.5 & 0.246 \\
\hline $\begin{array}{l}\text { Provision of training programs for hand tools and } \\
\text { equipment use }\end{array}$ & 4.8 & 0.261 \\
\hline Provision of fire detection system & 5 & 0.149 \\
\hline Provision of alarm system & 4.6 & 0.138 \\
\hline Need of firefighting training and emergency plan & 4.5 & 0.136 \\
\hline Need of extinguishing system & 4.7 & 0.141 \\
\hline Provision of emergency Exit and exit signs & 4.8 & 0.144 \\
\hline Covered electrical cables & 5 & 0.149 \\
\hline Proper electrical wiring & 4.8 & 0.144 \\
\hline Provision of safe and proper type of truck & 4.8 & 0.249 \\
\hline Safe cranes and conveyors & 4.7 & 0.244 \\
\hline Need of inspection schedule & 5 & 0.258 \\
\hline Provision of safe storage and stacking & 4.8 & 0.249 \\
\hline Skin contact with liquid chemicals & 4.4 & 0.246 \\
\hline Exposure to noise and vibration & 4.4 & 0.246 \\
\hline Exposure to high thermal conditions & 4.3 & 0.241 \\
\hline Monitoring of occupational exposures & 4.7 & 0.267 \\
\hline Adequate provision of PPE & 5 & 0.252 \\
\hline Proper types and use of PPE & 4.8 & 0.243 \\
\hline Proper maintenance of PPE & 5 & 0.252 \\
\hline Adequate training on PPE usage & 5 & 0.252 \\
\hline Availability of safe drinking water & 5 & 0.252 \\
\hline Availability of clean bathrooms, toilets, urinals & 4.9 & 0.248 \\
\hline Availability of rest area, canteen and closets & 4.9 & 0.248 \\
\hline Provision of proper lighting and ventilation & 5 & 0.252 \\
\hline
\end{tabular}

Table 4: Weight and mean values of factors and sub factors for safety index.

\section{Future scope}

- A similar application can be devised, developed and analyzed by replacing the medium scale iron and steel industry with another type of industry i.e. hand tool industry, fastener industry.

By taking the different kind of factors into consideration like vibration effect, hearing effect, temperature effect, etc. we also can proceed for further research.

\section{References}

1. Mutual $L$ (2008) Workplace safety index. From Research to Reality.

2. Kevin LX, Yin J, Fan L (2014) Ship safety index. Transportation research part A policy and practice 66: 75-87.
3. Chang $\mathrm{YH}$, Yeh $\mathrm{CH}$ (2004) A new airline safety index. Transportation Research Part B: Methodological 4: 369-383.

4. Hwang I (2005) Development of a safety index of transarterial chemoembolization for hepatocellular carcinoma to prevent acute liver damage. Anticancer Research 25: 2551-2554.

5. Maroño M, Pena JA, Santamaria JS (2006) The PROCESO index: a new methodology for the evaluation of operational safety in the chemical industry. Reliability Engineering \& System Safety 3: 349-361.

6. Jamson J, Samantha S (2008) Developing a driving Safety Index using a Delph stated preference experiment. Accident Analysis \& Prevention 2: 435-442.

7. Pacheco, Rodrigues R, Fernandes E, Domingos EM (2014) Airport airside safety index. Journal of Air Transport Management 34: 86-92.

8. Nagar E Riham, Hossam Hosny, Askar HS (2015) Development of a Safety 
Citation: Singh S, Singh LP (2017) Occupational Safety Culture of Workers at Shop Floor in Medium Scale Iron and Steel Industries of Punjab State in India: Development of Safety Index. J Steel Struct Constr 3: 126. doi: 10.4172/2472-0437.1000126

Performance Index for Construction Projects in Egypt. American Journal of Civil Engineering and Architecture 5: 182-192.

9. Abolfazl G, Khalkhali HR (2015) Development and Validation of a Safety Climate Scale for Manufacturing Industry. Safety and Health at Work 2: 97-103.

10. Seo DC, Torabi MR, Blair EH, Ellis NT (2004) A cross-validation of safety climate scale using confirmatory factor analytic approach. Journal of Safety Research 4: 427-445.

11. Gabryelewicz GI, Sadłowska-Wrzesińska J, Kowal E (2015) Evaluation of Safety Climate Level in a Production Facility. Procedia Manufacturing 3: 5822 5829.

12. Silva S, Lima ML, Baptista C (2004) OSCI an organizational and safety climate inventory. Safety Science 42: 205-220.

13. Noweir MH, Alidrisi MM, AI-Darrab IA, Zytoon MA (2013) Occupational safety and health performance of the manufacturing sector in Jeddah Industrial Estate, Saudi Arabia A 20-years follow-up study. Safety Science 53: 11-24.

14. Maroño M, Pena JA, Santamaria J (2006) The PROCESO index a new methodology for the evaluation of operational safety in the chemical industry. Reliability Engineering \& System Safety 91: 349-361.

15. Wang L, Sun R (2012) The development of a new safety culture evaluation index system. Procedia Engineering 43: 331-337.

16. Polit DF, Beck CT (2006) The content validity index are you sure you know what's being reported? Critique and recommendations. Research in Nursing \& Health 5: 489-497.

17. Davis LL (1992) Instrument review getting the most from your panel of experts. Applied Nursing Research 5: 194-197.

18. Lynn MR (1986) Determination and quantification of content validity. Nursing Research 35: 382-385.
19. Grant JS, Davis LT (1997) Selection and use of content experts in instrument development. Research in Nursing \& Health 20: 269-274.

20. Keeney S, Hasson F, Mckenna HP (2001) A critical review of the Delphi technique as a research methodology for nursing. International Journal of Nursing Studies 38: 195-200.

21. Cuhls K, Blind K (1999) Die Delphi-Methodeals Instrument der Technikfolgenabschätzung. Handbuch Technikfolgenabschätzung. Edition Sigma, Berlin 2: 545-550.

22. Wentholt MT, Fischer AR, Rowe G, Marvin HJ, Frewer LJ (2010) Effective identification and management of emerging food risks Results of an international Delphi survey. Food Control 21: 1731-1738.

23. Filip J (2011) Perspectives on CO2 capture and storage. Greenhouse Gases Science and Technology 2: 119-133.

24. Chu HC, Hwang GJ (2008) A Delphi-based approach to developing expert systems with the cooperation of multiple experts. Expert systems with applications 34: 2826-2856.

25. Abimbola WO, Iwuagwu S (2015) Using Delphi Technique and the P-Process model to assess health communication programmes in Nigeria. African Evaluation Journal 2: 8.

26. Polit DF, Beck CT (2004) Nursing research Principles and methods. ( $7^{\text {th }}$ edn), Lippincott, Williams, \& Wilkins, Philadelphia.

27. Waltz CF, Strickland OL, Lenz ER (2005) Measurement in nursing and health research. (3rd edn), Springer Publishing Co New York.

28. Wynd CA, Schmidt B, Schaefer MA (2003) Two quantitative approaches for estimating content validity. Western Journal of Nursing Research 25: 508-518. 